\title{
Linear programming can help identify practical solutions to improve the nutritional quality of food aid
}

\author{
Zo J Rambeloson ${ }^{1}$, Nicole Darmon ${ }^{2, *}$ and Elaine L Ferguson ${ }^{3}$ \\ ${ }^{1}$ Linkages/AED, Antananarivo, Madagascar: ${ }^{2}$ Nutrition Research Unit 476 INSERM/1260 INRA, 27 Boulevard \\ Jean Moulin, F-13385 Marseille Cedex 05, France: ${ }^{3}$ Department of Human Nutrition, University of Otago, \\ Dunedin, New Zealand
}

Submitted 28 November 2006: Accepted 2 May 2007: First published online 1 August 2007

\begin{abstract}
Objectives: To assess the nutritional quality of food aid delivered by food banks in France and to identify practical modifications to improve it.

Design: National-level data were collected for all food aid distributed by French food banks in 2004, and its nutrient content per $2000 \mathrm{kcal}$ was estimated and compared with French recommendations for adults. Starting with the actual donation and allowing new foods into the food aid donation, linear programming was used to identify the minimum changes required in the actual donation to achieve the French recommendations.

Results: French food-bank-delivered food aid does not achieve the French recommendations for dietary fibre, ascorbic acid, vitamin D, folate, magnesium, docosahexaenoic acid, $\alpha$-linolenic acid and the percentage of energy from saturated fatty acids. Linear programming analysis showed that these recommendations are achievable if more fruits, vegetables, legumes and fish were collected and less cheese, refined cereals and foods rich in fat, sugar and/or salt. In addition, new foods not previously collected are needed, particularly nuts, wholemeal bread and rapeseed oil. These changes increased the total edible weight (42\%) and economic value (55\%) of the food aid donation, with one-third of its edible weight coming from fruits and vegetables, one-third from staples, one-quarter from dairy products and approximately a tenth from meat/fish/eggs.

Conclusions: Important changes in the types and amounts of food collected will improve the nutritional quality of food-bank-delivered food aid in France. Such changes are recommended to improve the diets of deprived French populations.
\end{abstract}

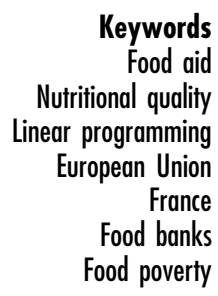

In France, $12 \%$ of households live under the income poverty level ${ }^{1}$; and an estimated 2.6 million individuals annually seek food aid. These statistics suggest an important level of food insecurity, which is of concern because poverty ${ }^{2}$ and food insecurity ${ }^{3,4}$ are associated with increased risks of nutritional deficiencies and poor health. As a result, the French Nutrition and Health National Programme 5 specifically aims to decrease vitamin and mineral deficiencies and malnutrition in deprived populations, in particular by sustaining food aid programs adapted to their needs'.

The complex French food aid system is delivered via poorly connected private organisations. Notwithstanding, the French food bank (FB) network, which is composed of $79 \mathrm{FBs}$ scattered throughout the country, is by far the largest organisation, providing approximately half of the total quantity of food aid delivered in France ${ }^{6}$. Unlike other food aid organisations, the French FB network does not deliver foodstuffs directly to food recipients, but instead supplies it to one out every two local food aid organisations $^{7}$. It obtains its foodstuffs from the European Union (EU) programme of aid to the deprived person and from local French networks, including private individuals, farmers, food manufacturers and supermarkets ${ }^{8}$. The food aid from the EU, which makes up an important proportion of the FB foodstuffs, is from an overproduction of European agricultural products, and includes only negligible amounts of fruits, vegetables and fish. To ensure the nutritional quality of the French FB food aid donations, therefore, requires purposeful foodstuffs selection from the local networks in France.

A powerful analytical approach, which can be used to identify foodstuffs required to ameliorate nutritional imbalances in the French FB food aid donations, is linear programming analysis (LP). Starting from a list of foods of known nutritional composition, a nutritionally optimal combination of foods is mathematically selected via a linear optimisation function, subject to linear constraints. 
In earlier studies, LP was used to design nutritious lowcost diets ${ }^{9,10}$ and identify the 'best' dietary changes for achieving nutrient recommendations, while deviating the least from individual ${ }^{11,12}$ or population ${ }^{13,14}$ dietary habits. More recently, it was used to identify the limiting foods and limiting nutrients in a population's diet ${ }^{15,16}$, to analyse the impact of economic constraints on food choices $^{17,18}$ and to rigorously develop food-based dietary guidelines $^{19}$. In the current study, both the cost and the nutrient content of a French FB food aid donation are linearly related to the weights of food collected (edible weight). Thus, LP can be used to rapidly explore the cost or nutritional implications of alternative optimised food aid combinations. In other words, it can be used to rapidly identify specific food collection strategies that will ensure the French FB food aid donations are nutritionally adequate and that the French Nutrition and Health National Programme goals are realised. The advantage of using LP for this purpose is that the minimum changes required to improve the nutritional balance of FB-delivered food aid in France can be identified, which will help facilitate implementation.

Thus, the objectives of the current study were first to analyse the nutritional quality of FB-delivered food aid in France, and then to identify practical modifications, using LP, that would improve it.

\section{Methods}

\section{The data}

Data on the types and quantities (in tonnes) of foodstuffs distributed by the French FB network in 2004 were collected from the following sources: for the EU donation, from the EU annual activity report available at the European information centre 'la Source de l'Europe' (La Défense, France); and for the French supply-channel donations, from the archives of the French Federation of Food Banks (Gentilly, France). In addition, in 2004, five key informants, who were working at FBs in the cities of Montpellier, Nantes, Strasbourg and Paris, were asked to identify acceptable foodstuffs that were not currently collected, but which could be collected via the French FB network. Specifically, key informants were asked to select new foods from the SUVIMAX food composition table ${ }^{20}$ that $\mathrm{FB}$ recipients (i.e. local food aid organisations) would accept. These new foods were then allowed into the final LP model (i.e. complete model; see below) to identify foodstuffs that, if added to the FB donations, would help ensure a nutritionally adequate French FB food aid donation.

In all analyses, food weights were expressed per edible fraction; their contents of energy and nutrients were obtained from the SUVIMAX food composition table ${ }^{20}$; and their mean retail prices were estimated using mean national retail prices from the French Institute of Statistics (INSEE), marketing research (SECODIP) or supermarket websites. These data were used to estimate the nutrient content, energy density and economic value per edible fraction of the actual and modelled French FB food aid donations. Energy density ( $\mathrm{kcal} / 100 \mathrm{~g}$ ) was calculated by dividing the energy content of the total edible food donation by its estimated edible weight.

\section{Evaluation of the nutrient content and economic value of $\mathrm{FB}$ food aid donation}

Nutrient contents were calculated for the EU donation, and for all food aid delivered by FBs in France (i.e. the EU donation plus the FB collection). The specific macronutrients examined were proteins, lipids, saturated fatty acids (SFA) and carbohydrates; and the micronutrients examined were vitamins A, D, E, C, B $\mathrm{B}_{1}, \mathrm{~B}_{2}, \mathrm{~B}_{6}, \mathrm{~B}_{12}$, folate, magnesium, calcium and iron. Dietary fibre, 18:2n-6 (linoleic acid), 18:3n-3 ( $\alpha$-linolenic acid) and 22:6n-3 (docosahexaenoic acid; DHA) were also examined. To evaluate the nutritional adequacy of the food aid donation, its nutrient content per $2000 \mathrm{kcal}$ was estimated and compared with the French recommended dietary allowances, the ANC (Apports Nutritionnels Conseillés), averaged for 20-65-year-old men and women ${ }^{21}$. The relative edible weight contributions from six food groups (meat/ fish/eggs, fruit and vegetables, dairy products, staples, sugar/salt, added fats) and five subgroups (fish, nuts/ dried fruits, cheese, unrefined staples, vegetable fats) were evaluated and expressed as percentages of the total edible weight. These food groups were selected because their nutrient content and energy density were relatively homogeneous. Statistical analyses were not conducted because the total food donation delivered in 2004 instead of a sample of it was examined.

\section{Optimising the nutritional quality of food aid}

LP techniques similar to those described in more detail elsewhere ${ }^{16,22}$ were used to select, via diet optimisation, nutritionally adequate FB food aid donations for adults. In these LP models, nutritional adequacy for FB food aid donations expressed per $2000 \mathrm{kcal}$ of energy was ensured, in all feasible model solutions, via nutritional constraints defined as the averaged ANC recommendations for all nutrients (see Table 1). For vitamin A, an upper limit corresponding to the upper tolerable level recommended in France ${ }^{21}$ was imposed to avoid the high levels of vitamin A that are often selected in modelled LP diets.

Overall, three different sets of LP models were run, which were defined by their eligible food lists. In the first model (i.e. EU model), only foods provided in the EU donation were eligible. In the second model (i.e. EUFB model), all foods distributed by the FBs (i.e. EU donation and FB collections) were eligible. In the third model (i.e. complete model), all foods distributed by the FBs (i.e. EU donation and FB collections) and new foods selected by the key informants were eligible. The decision variables 
in all models were the edible grams of foods selected. Compared with the actual donation, the optimised donation's food weight will probably increase, because healthy diets are less energy-dense than diets of poor dietary quality ${ }^{23,24}$. Most food aid organisations have limited capacities for transporting and stocking foodstuffs, especially perishable or frozen foods. Thus, for long-term acceptability and depending on the model, the objective functions minimised either the total food donation weight or the edible food weight difference for each food (in tonnes) between the optimised donation and the actual donation of 2004. The three different model types are described in detail below.

- The EU model was designed to test whether it was possible, via an increase in the EU-donated food weights (in tonnes), to achieve a nutritionally adequate EU donation. The decision variables were all foodstuffs received from the $\mathrm{EU}$, i.e. the $\mathrm{EU}$ food donation. Constraints ensured that each eligible EU food was selected at a weight that was greater than its actual weight in the 2004 EU donation. Upper constraints on food weights were not applied. Thus, to achieve a nutritionally adequate donation (expressed per $2000 \mathrm{kcal}$ ), EU foods could be freely added to the actual EU donation. The objective function minimised the total weight of the optimised donation.

- The EUFB model was designed to test whether it was possible to achieve a nutritionally adequate donation when only weights (in tonnes) of the locally collected foodstuffs (i.e. FB collections) were allowed to increase. In this model, the EU food donation weights were entered as constants, i.e. not allowed to change, because the EU donation is more difficult to change than the food donations collected in France. The decision variables were all FB foods collected via the French supply channels, i.e. foods from the FB collection. To avoid unrealistic changes, constraints limited the weight range for each FB food from greater than its actual weight in the $2004 \mathrm{FB}$ collection to less than 20 times this weight. Similar to the EU model, the objective function of the EUFB model minimised the total weight of the optimised donation.

- The complete model was designed to obtain a nutritionally adequate optimised donation that differed as little as possible from the actual EUFB donation. In this model, unlike the previous models, both increases and decreases in the FB collection food weights were allowed and the selected new foods (from key informants) could enter the optimised donation. Similar to the EUFB model, the EU donation food weights were entered as constants, because of the presumed difficulties in changing their donated amounts. The decision variables, in this model, were both the FB collection foods and the list of new foods selected by the key informants. The objective function selected a nutritionally adequate optimised donation that resembled the actual donation as closely as possible. Specifically, it minimised the sum of absolute values for the differences between optimised and actual modifiable food weights (i.e. FB collection foods and new foods). This function was transformed into a linear function as previously described in detail elsewhere ${ }^{17}$. Here the actual food weights, i.e. before optimisation, for the new foods were set at zero, and for the FB collection foods were set at their donated weights. The optimised food donation, i.e. the solution, indicated the smallest weight changes required from the original EUFB donation to achieve nutrient adequacy, including increases and decreases in the quantities of foodstuffs currently collected, and new foods that should be collected in the donation. In this model, to ensure a realistic donation, maximum level constraints on food weights were applied. For FB collection foods, the maximum allowable weights were $200 \%$ of each food's donated weight in 2004, and for each new food, its maximum allowable weight was 500 tonnes, except for bread (maximum 4000 tonnes) and dried fruits and condiments (maximum 100 tonnes). These limits for new foods were close to quantities of similar products already distributed by FBs. In addition, a lower-level constraint on energy was introduced to ensure the energy content of the optimised donation was greater than or equal to that of the actual donation.

All LP models were run using the Simplex procedure of the Premium Solver 3.5 for Excel (Frontline Systems).

\section{Results}

\section{Nutritional quality of the actual donations}

In 2004, the French FB network delivered 59279 tonnes of EUFB foodstuffs, of which 16679 tonnes (28\%) came from 21 foodstuffs donated by the EU and 42601 tonnes (72\%) came from 66 foodstuffs collected through FB channels in France. Fourteen foods were in both the EU donation and the $\mathrm{FB}$ collection, providing a total of 73 different foods. In the EU donation, the percentages of energy provided by macronutrients were $17 \%$ from proteins, $41 \%$ from lipids, $22 \%$ from SFA and 43\% from carbohydrates (Table 1). Moreover, in the EU donation, 12 out of 16 nutrients were below the ANC recommended levels (expressed per $2000 \mathrm{kcal}$ ). Notably, the dietary fibre, 18:3n-3, DHA, vitamin D, vitamin E, vitamin C and folate contents were only 36\%, 39\%, 7\%, 19\%, 37\%, 14\% and $35 \%$ of their corresponding ANC values, respectively. In the EUFB donation (i.e. EU donation plus FB collections), the percentages of energy provided by macronutrients were $17 \%$ from proteins, 39\% from lipids, $17 \%$ from SFA and 45\% from carbohydrates (Table 1). In this donation, 10 of 16 nutrients were below their ANC 
Table 1 Energy density, cost of energy and nutrient contents in $2000 \mathrm{kcal}$ of the 2004 food aid donation from the European Union (EU donation), of all food aid delivered by food banks in France (i.e. the EU donation plus the collection from French food banks, EUFB donation) and of the food aid donation optimised with the 'complete' model (optimised donation)

\begin{tabular}{|c|c|c|c|c|}
\hline & EU donation & EUFB donation & LP constraints* & Optimised donation \\
\hline Energy density (kcal/100 g) & 162 & 161 & - & 113 \\
\hline Cost of energy ( $€ / 2000 \mathrm{kcal})$ & 2.40 & 2.75 & - & 4.24 \\
\hline \multicolumn{5}{|l|}{ Macronutrients } \\
\hline Proteins (\% of total energy) & 16.7 & 16.8 & & 20.0 \\
\hline Total fat (\% of total energy) & 41.1 & 38.6 & $<35$ & 31.3 \\
\hline Saturated fatty acids (\% of total energy) & 21.8 & 16.5 & $<12$ & 12.0 \\
\hline Carbohydrates (\% of total energy) & 42.6 & 45.3 & & 50.4 \\
\hline Added sugars ( $\%$ of total energy) & 0.4 & 7.8 & $<10$ & 4.0 \\
\hline \multicolumn{5}{|l|}{ Fibre and essential fatty acids } \\
\hline Fibre $(\mathrm{g})$ & 10.8 & 17.9 & $>30$ & 36.2 \\
\hline 18:2n-6, linoleic acid $(\mathrm{g})$ & 4.8 & 14.4 & $>9$ & 9.0 \\
\hline $18: 3 n-3, \alpha$-linolenic acid $(\mathrm{g})$ & 0.7 & 0.7 & $>1.8$ & 1.8 \\
\hline $22: 6 n-3$, docosahexaenoic acid $(\mathrm{g})$ & 0.01 & 0.03 & $>0.11$ & 0.38 \\
\hline $18: 2 n-6 / 18: 3 n-3$ & 6.9 & 20.3 & $<6$ & 5.0 \\
\hline \multicolumn{5}{|l|}{ Micronutrients } \\
\hline Magnesium (mg) & 202 & 221 & $>390$ & 390 \\
\hline Calcium (mg) & 1044 & 1197 & $>900$ & 1060 \\
\hline Iron (mg) & 8.7 & 10.1 & $>13$ & 14.2 \\
\hline Vitamin A $(\mu \mathrm{g})$ & 957 & 1341 & $>700+$ & 1800 \\
\hline Vitamin D $(\mu \mathrm{g})$ & 0.9 & 0.8 & $>3$ & 4.2 \\
\hline Vitamin E (mg) & 4.4 & 14.3 & $>12$ & 12.0 \\
\hline Vitamin C (mg) & 15 & 44 & $>110$ & 125 \\
\hline Vitamin $B_{1}(\mathrm{mg})$ & 0.9 & 1.0 & $>1.2$ & 1.5 \\
\hline Vitamin $B_{2}(\mathrm{mg})$ & 1.8 & 1.9 & $>1.6$ & 1.9 \\
\hline Vitamin $B_{6}(\mathrm{mg})$ & 1.2 & 1.5 & $>1.7$ & 2.2 \\
\hline Vitamin $B_{12}(\mu \mathrm{g})$ & 4.5 & 4.2 & $>2.4$ & 5.55 \\
\hline Folate $(\mu \mathrm{g})$ & 111 & 188 & $>315$ & 367 \\
\hline
\end{tabular}

*Nutritional constraints included in the linear programming (LP) models.

$+\mathrm{A}$ maximal content of $1800 \mu \mathrm{g}$ was also imposed for vitamin A.

recommendations (expressed per $2000 \mathrm{kcal}$ ). Notably, the dietary fibre, 18:3n-3, DHA, vitamin D and vitamin C contents were only $60 \%, 39 \%, 24 \%, 28 \%$ and $40 \%$ of their corresponding ANC values, respectively. In addition, the $18: 2 n-6 / 18: 3 n-3$ ratio of 20.32 in the EUFB donation was well above the maximum of 6 recommended for a healthy diet.

\section{Optimisation with the EU model}

The LP results showed that an optimised EU model was infeasible, which confirms that a nutritionally adequate EU donation is impossible even when unlimited increases in food quantities are allowed. The nutritional constraints that made the model infeasible were those on dietary fibre, 18:3n-3, DHA, vitamin D, vitamin E and vitamin C, which were $53 \%, 33 \%, 13 \%, 15 \%, 95 \%$ and $44 \%$ of their recommended levels, respectively, in the final nonfeasible solution (i.e. the best solution that could be achieved). In addition, its $18: 2 n-6 / C 18: 3 n-3$ ratio of 22.9 and the SFA content of $13.7 \%$ of total energy did not achieve recommendations.

\section{Optimisation with the EUFB model}

The LP results showed that an optimised EUFB model was also infeasible. The nutritional constraints that made this model infeasible were those defining the minimum contents of 18:3n-3, DHA and vitamin D, which were 93\%, $20 \%$ and $24 \%$ of their recommended levels in the final non-feasible solution, respectively; as well as the maximum constraints on the SFA content and 18:2n-6/ C18:3n-3 ratio (i.e. 8.6 vs. 6). Among the 66 eligible FB foods variables, the weights of only seven were increased. These foods were: fortified cereals rich in dietary fibre, vegetable soup (UHT bottle), tomato paste, mustard, tomatoes, bananas and cauliflowers. All, except bananas, were selected at their maximum allowed weights (i.e. 20 times their actual weights).

\section{Optimisation with the complete model}

The key informants selected 127 new foods that FB recipients would accept, which could be collected via the FB network. Allowing these new foods into the model, as well as increases and decreases in FB collections, resulted in a feasible complete model solution. Thus, a nutritionally adequate FB food donation is achievable. Compared with the actual donation, the total weight and economic value of the optimised donation increased by $42 \%$ and $55 \%$, respectively; this decreased its energy density and increased its dietary energy cost compared with the EU and EUFB donations (Table 1). The limiting nutrients (i.e. their constraint levels were just fulfilled) were the maximum level allowed for SFA and the minimum level imposed on 18:2n-6, 18:3n-3, magnesium and vitamin $\mathrm{E}$. The changes required to achieve nutrient adequacy in the complete model are shown in Table 2. As shown, 33\% of 
Table 2 The list of potential French food bank network foods modelled in the 'complete' model expressed as their amounts (in tonnes, $t$ ) selected in the optimised donation and, for those collected in 2004, as a percentage of their 2004 donated amounts*

\begin{tabular}{|c|c|c|c|c|}
\hline Food group & $\begin{array}{l}\text { Collected foods whose amounts should } \\
\text { be decreasedt }\end{array}$ & $\begin{array}{l}\text { Collected foods whose amounts } \\
\text { should be unchanged }\end{array}$ & $\begin{array}{l}\text { Collected foods whose amounts should } \\
\text { be increased }\end{array}$ & New foods to introduce \\
\hline Meat/fish/eggs & $\begin{array}{l}\text { Mashed steak, } 15 \% \text { fat: } 0 \mathrm{t}(0 \%) \\
\text { Corned beef: } 0 \mathrm{t}(0 \%)\end{array}$ & $\begin{array}{l}\text { Eggs: } 53 \mathrm{t}(100 \%) \\
\text { Chicken: } 1991 \mathrm{t}(100 \%) \\
\text { Ham: } 242 \mathrm{t}(100 \%) \\
\text { Chicken nuggets: } 18 \mathrm{t}(100 \%)\end{array}$ & $\begin{array}{l}\text { Cod, frozen: } 152 \mathrm{t}(200 \%) \\
\text { Pollock, frozen: } 250 \mathrm{t}(200 \%) \\
\text { Sardine, canned: } 185 \mathrm{t}(200 \%) \\
\text { Tuna, canned: } 152 \mathrm{t}(200 \%)\end{array}$ & $\begin{array}{l}\text { Mashed steak, } 5 \% \text { fat: } 500 \mathrm{t} \\
\text { Lean beefsteak: } 500 \mathrm{t} \\
\text { Rabbit: } 500 \mathrm{t} \\
\text { Fish soup: } 500 \mathrm{t} \\
\text { Trout: } 500 \mathrm{t} \\
\text { Salmon, frozen: } 500 \mathrm{t} \\
\text { Salmon, smoked: } 500 \mathrm{t}\end{array}$ \\
\hline Fruits and vegetables & Stewed apples: $0 \mathrm{t}(0 \%)$ & $\begin{array}{l}\text { Vegetables soup: } 85 \mathrm{t}(100 \%) \\
\text { Peaches: } 12 \mathrm{t}(100 \%) \\
\text { Apples: } 3986 \mathrm{tt}(100 \%) \\
\text { Dry raisins: } 12 \mathrm{t}(100 \%) \\
\text { Mixed fruits, canned: } 3 \mathrm{t}(100 \%)\end{array}$ & $\begin{array}{l}\text { Carrots, canned: } 2748 \mathrm{t}(155 \%) \\
\text { Minestrone, bottle: } 397 \mathrm{t}(200 \%) \\
\text { Artichoke: } 52 \mathrm{t}(200 \%) \\
\text { Cauliflower: } 704 \mathrm{t}(20 \%) \\
\text { Endives, fresh: } 1184 \mathrm{t}(200 \%) \\
\text { Tomato: } 120 \mathrm{t}(200 \%) \\
\text { Tomato paste: } 315 \mathrm{t}(200 \%) \\
\text { Green beans, canned: } 152 \mathrm{t}(200 \%) \\
\text { Peas, canned: } 5593 \mathrm{t}(200 \%) \\
\text { Banana: } 2565 \mathrm{t}(200 \%) \\
\text { Orange juice: } 1040 \mathrm{t}(200 \%) \\
\text { Dry apricots: } 47 \mathrm{t}(200 \%) \\
\text { Dates: } 53 \mathrm{t}(200 \%)\end{array}$ & $\begin{array}{l}\text { Carrots, fresh: } 500 \mathrm{t} \\
\text { Cucumber: } 500 \mathrm{t} \\
\text { Beetroots: } 500 \mathrm{t} \\
\text { White cabbage: } 500 \mathrm{t} \\
\text { Onion soup: } 500 \mathrm{t} \\
\text { Tomato soup: } 500 \mathrm{t} \\
\text { Brussels sprouts: } 500 \mathrm{t} \\
\text { Broccoli: } 500 \mathrm{t} \\
\text { Spinach: } 500 \mathrm{t} \\
\text { Lamb's lettuce: } 100 \mathrm{t} \\
\text { Mixed vegetables, canned: } 500 \mathrm{t} \\
\text { Kiwi: } 500 \mathrm{t} \\
\text { Strawberry: } 500 \mathrm{t} \\
\text { Dry prunes: } 100 \mathrm{t} \\
\text { Dry figs: } 100 \mathrm{t} \\
\text { Nuts: } 100 \mathrm{t}\end{array}$ \\
\hline
\end{tabular}

\section{Mixed dishes}

Milk and dairy products

Cheese spread: 0t $(0 \%)$

Emmental: $426 \mathrm{t}(45 \%)$

Staples

White sandwich bread: $0 \mathrm{t}(0 \%)$

White bread: $406 \mathrm{t}(43 \%)$

Rusk: $0 \mathrm{t}(0 \%)$

White rice: $0 \mathrm{t}(0 \%)$

Sugar: 0 t $(0 \%)$

Croissant: 0 t $(0 \%)$

Cookies: 0 t $(0 \%)$

Honey: 0 t $(0 \%)$

Marmalade: $0 \mathrm{t}(0 \%)$

Sweet beverages: ot $(0 \%)$

Sweet concentrated milk: $0 t(0 \%)$
Sugar and sweets
Raviolis with beef: $930 \mathrm{t}(100 \%) \quad$ Beef and vegetables: $1404 \mathrm{t}(125 \%)$

Dairy desserts (2 sorts): $791 \mathrm{t}$ $(100 \%)$

Milk, semi-fat UHT: $5162 \mathrm{t}(100 \%)$

Sweet yoghurt: 1945t (100\%)

White pasta: 1170 t (100\%)

Semolina: 270 t (100\%)
RTE cereals, fibre-rich: $264 \mathrm{t}(200 \%)$ Dried mashed potatoes: $651 \mathrm{t}(200 \%)$ Fresh potatoes: $5960 \mathrm{t}(200 \%)$ Lentils, canned: $38 \mathrm{t}(200 \%)$ Haricot beans, canned: $88 \mathrm{t}(200 \%)$

Dark chocolate: 1028 t (200\%) 
the foods currently collected via the French FB network were excluded, including all sugars and highly sweetened foods (except dark chocolate), most added fats, fatty sauces, fatty meats, salty crackers, pâté, cheese spread and some refined cereals (Table 2). In contrast, approximately $40 \%$ of the FB foods were increased to the maximum level allowed, i.e. 200\%, including frozen and tinned fish, most fruits and vegetables, powdered skimmed milk, tinned legumes and potatoes (Table 2). In addition, 35 of the 127 new foods selected were included in the optimised model solution, generally at their maximum allowable weight. The new foods included lean meats, frozen and smoked salmon, nuts, 15 kinds of fruits and vegetables, wholemeal bread, tinned dwarf kidney beans, $0 \%$ fat dairy products, rapeseed and mixed vegetable oils (Table 2).

\section{Food contents of the actual and optimised donations}

The relative edible weights of different food groups and subgroups (expressed as percentages) in the actual EU and EUFB donations and in the optimised complete model donation are shown in Fig. 1 and Table 3. The EU donation was clearly unbalanced, because it had a low percentage weight of fruits and vegetables, nuts/dried fruits, fish, unrefined staples and vegetable oils, and generous amounts of refined cereals (39\% of the total EU donation), dairy products ( $42 \%$ of the total EU donation; which were mainly milk and cheese) and other animal-source foods, such as butter and beef. Foods collected through the French FB channels, to produce the EUFB donation, increased the relative amounts of fruits and vegetables and decreased the relative amounts of dairy products (but increased cheese), refined cereals, total staples and total added fats. As shown in Table 1, these changes improved the nutritional quality of the 2004 EUFB donation compared with the EU donation. Nevertheless, it still contained a relatively high percentage of foods that were high in sugar and/or salt (i.e. 7\%), which were reduced in the optimised complete model donation ( $2 \%$ of total edible weight). In the optimised complete model, there was also a reduction in the relative weight of added fats ( $1 \%$ of total edible weight, half of which were vegetable fats) and dairy products $(<5 \%$ were cheese), and an increase in the relative weights of fruits and vegetables (1\% were nuts/ dried fruits), unrefined staples and fish (30\% of the meat/ fish/eggs group was fish) compared with the EU and EUFB donations (see Fig. 1 and Table 3).

\section{Discussion}

The results from this study showed that the nutritional quality of French FB-delivered food aid, as shown in other countries $^{25-27}$, did not achieve nutritional recommendations. 


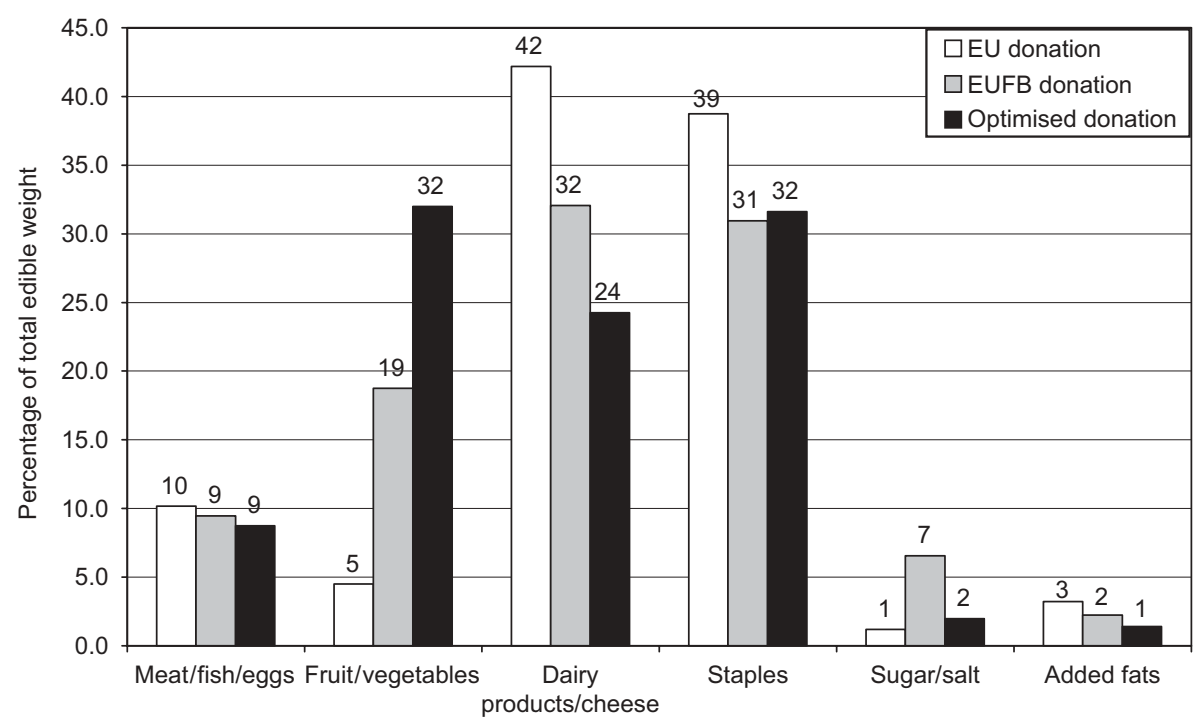

Fig. 1 Percentage (edible) weight of food groups in the 2004 food aid donation from the European Union (EU donation), for all food aid delivered by food banks in France (i.e. the EU donation plus the collection from French food banks, EUFB donation) and the food aid donation optimised with the 'complete' model (optimised donation)

Table 3 Percentage (edible) weight of specific food subgroups, within food groups, in the 2004 food aid donation from the European Union (EU donation), in all food aid delivered by food banks in France (i.e. the EU donation plus the collection from French food banks, EUFB donation) and in the food aid donation optimised with the 'complete' model (optimised donation)

\begin{tabular}{lcrr}
\hline$\%$ of subgroup in group & EU donation & EUFB donation & Optimised donation \\
\hline Fish, within Meat/fish/eggs & 0.0 & 5.4 & 28.8 \\
Nuts/dried fruits, within in Fruit and vegetables & 0.0 & 0.4 & 1.2 \\
Cheese, within Dairy products & 4.2 & 16.7 & 3.5 \\
Unrefined staples, within Staples & 0.0 & 24.1 & 54.2 \\
Vegetable fats, within Added fats & 0.0 & 52.5 & 49.5 \\
\hline
\end{tabular}

In particular, its SFA content was high and its contents of dietary fibre, vitamins $\mathrm{C}$ and $\mathrm{D}$, folate, magnesium, DHA and 18:3n-3 were low compared with French recommendations. Thus, the French FB collections did not sufficiently ameliorate the nutritional imbalances of the EU donation resulting from its negligible amounts or absence of fruits, vegetables, fish, vegetable fats and unrefined staples. Furthermore, our results mathematically confirmed that it was impossible, using only foods donated from the EU (EU model) and the FB collections (EUFB model), to design a nutritionally adequate food aid donation. Thus, to achieve the French Nutrition and Health National Programme goal - of decreasing micronutrient deficiencies among deprived populations in France via food aid programmes - will require marked changes in the French FB collections.

Our complete model results showed that improving the nutritional quality of $\mathrm{FB}$ food aid in France will require increased FB collections of fruits, vegetables, fish and lean meats, and decreased FB collections of foods high in SFA, sugar or salt, as well as substitutions of whole-grain cereals and legumes for refined cereals, low-fat dairy products for cheese, and vegetable oils rich in $n-3$ fatty acids for added fats rich in $n-6$. As shown in our model, such changes will likely increase the weight and economic value per unit energy (e.g. $42 \%$ and 55\%, respectively, in our complete model) of the FB collection, because diets of high nutritional quality often cost more and have a lower energy density than less healthy diets $^{28,29}$. Fruits, vegetables and fish are energy-dilute, nutrient-dense and expensive sources of energy; whereas foods rich in sugar, fat and/or salt are energy-dense, nutrient-poor and cheap sources of dietary energy ${ }^{30}$. Of note was the estimated economic value of the $2004 \mathrm{FB}$ food aid donation, which was close to the average food expenditure of people whose incomes fall below the poverty line in France, i.e. $2.75 €$ per 2000 kcal vs. $2.5 €$ per day $^{31}$; and well below the minimal cost required to achieve a nutritionally adequate diet recently estimated using LP, i.e. 3.18 and $3.31 €$ per day for French women and men, respectively ${ }^{14}$. Thus it was not surprising to find that the economic value of the complete model's optimised food donation was higher than the estimated value of the $2004 \mathrm{FB}$ food aid donation (i.e. $4.75 € / 2000 \mathrm{kcal} v \mathrm{vs}$. $2.75 € / 2000 \mathrm{kcal})$ and close to the current mean national expenditure for food at home (i.e. $4.9 €$ per day) ${ }^{32}$.

The estimated economic value of food aid presented here is only informative, because food items distributed 
through FB channels cannot be sold. In addition, their packages are often damaged or incorrectly labelled and/ or they are close to their use-by date ${ }^{26}$. Moreover, FBs out of principle will not purchase the foods they distribute. Free donations of fresh products are generally easier to obtain than canned products, even though the latter are more desirable because they are easier to transport, stock and distribute. Thus, strategies to increase canned food donations are required, such as publicising lists of practical and healthy foods during supermarket 'donation day' events to encourage private donations of non-perishable foodstuffs, such as canned fish and vegetables and rapeseed oil (or any other new, non-perishable foodstuff identified via the complete model). Nevertheless, longterm improvements in the nutritional quality of French FB-delivered food aid will probably require political decisions/pressures and fiscal incentives to persuade the EU or the French producers, food industries and food distributors to modify their donations. However, as long as the French FB food aid recipients, i.e. the private food aid organisations, continue to face budget, space and equipment constraints, FB donations will likely remain 'unhealthy' because food 'choices' are largely limited by economic $^{17}$ and physical $^{33}$ constraints. Thus, a more efficient way to support low-income people than private food aid organisations is perhaps required, such as institutionally distributed economic supplements or food vouchers, designated for the purchase of high-quality nutrient-dense fresh foods such as fruits and vegetables. A recent study showed that low-income women participating in the WIC (Women, Infants, and Children) programme in Los Angeles use such targeted subsidies wisely ${ }^{34}$.

There are notable similarities when comparing the composition of food aid and the diets of the poor in industrialised countries. For example, both are based on refined cereals, are low in fruits, vegetables and fish, and contain excessive amounts of foods rich in sugar and fats $^{35}$. Likewise, the nutrients low in the 2004 EUFB donation, notably vitamin $\mathrm{C}$ and folate, are also low in the diets of the poor ${ }^{2}$. Such similarities are not surprising, because organisations delivering food aid experience the same economic and physical barriers as those they are trying to help. Both rely on food donations (this is particularly true for FBs, because they will only accept donations or exchanges that do not involve money). Both face constraints in the amount of food, especially perishable and frozen foods, which can be transported and stored. Furthermore, with food aid, a nutritionally balanced food basket is more difficult to provide than balanced meals, because traditional rules of meal composition dictate acceptable food group combinations in meals. Accordingly, as recently shown in France, the nutritional quality of donated meals is higher than that of donated food baskets ${ }^{7}$; which is also perhaps exacerbated by the general lack of nutrition training among the paid or unpaid workers involved in organisations delivering food aid. Notwithstanding, the nutritional quality of donated food baskets can be improved using simple rules that are easy to understand and apply, which stipulate the relative weights of different food groups and subgroups in the total food basket. Although calculations are required to transform the donated food weights into their weights 'as eaten' (i.e. edible weights), the percentage edible weights (e.g. such as shown in Fig. 1 and Table 3) are more useful for designing or evaluating food baskets than the recommended food-based dietary guidelines, which are expressed as daily or weekly food group frequencies. Indeed, during their fourth national congress in October 2006, the French FB network decided to monitor and develop local, national and/or European strategies to improve the nutritional balance of FB-delivered food aid baskets, using an approach based on percentage edible food weights. The percentage weights they are currently recommending are shown in Fig. 2. Such percentages are compatible with the French food-based dietary guidelines $^{36}$ and the present LP results. By giving priority to meat, fish, vegetables and fruit, they also take into account the high cost of these food groups.

Delivering high-quality, nutrient-dense food aid is generally not the main objective of charitable organisations. Instead, food aid is often viewed as a source of calories, a form of economic support or a source of other non-nutritional benefits ${ }^{37}$. This perception needs to change, because poor-quality food aid may increase the risk of cardiovascular disease and other nutrition-related diseases common in populations of low socio-economic status $^{38}$. Indeed, the high prevalence of obesity among recipients of institutional food aid programmes in the USA was recently attributed to its poor nutritional quality ${ }^{37,39}$. Clearly, there is an urgent need to improve the nutritional quality of food aid delivered in France to improve the diets of recipients, including recipients who are only partially dependent upon it, because their diets are virtually devoid of fruits, vegetables, unrefined cereals and fish ${ }^{31}$. Such improvements will potentially have a favourable impact on the health of food aid recipients, both directly by providing them healthier foods and indirectly by showing them how to put into practice the

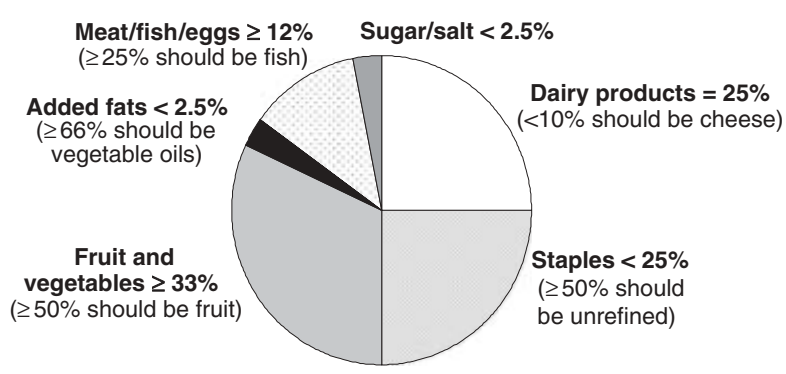

Fig. 2 The recommended food basket (in percentages of total edible weight) 
widely promoted and understood nutrition messages, including those the food aid organisations themselves promote. However, acting through private food aid organisations alone will not be sufficient to prevent food insecurity because food-insecure people often do not visit these organisations - either out of a lack of awareness of their existence or to avoid the social stigma ${ }^{40}$. In fact, Canadian researchers have shown that charitable food assistance may alleviate, but not prevent, food insecurity owing to its donor-driven nature or because the food demand surpasses its supply ${ }^{41}$.

In conclusion, important changes are required in the types and amounts of FB-collected food aid to improve the nutritional quality of FB-delivered food aid in France. In particular, more fruits, vegetables, legumes and fish should be collected and less cheese, refined cereals and foods rich in fat, sugar and/or salt, to ensure that food aid fulfils the French recommendations for dietary fibre, ascorbic acid, vitamin D, folate, magnesium, DHA, 18:3n-3 and the percentage of energy from SFA. Multiple actions should be undertaken to achieve this. Notably, efforts should focus on developing strategies that will increase specific kinds of food donations and on nutrition education programmes run to help FB volunteers design balanced food baskets using relative food group weights. Finally, a national food aid programme providing targeted subsidies for fresh products may be necessary.

\section{Acknowledgements}

Sources of funding: No specific funding.

Conflict of interest declaration: No conflict of interest.

Authorship responsibilities: Z.J.R. and N.D. conceived the study, supervised and completed the analysis, interpreted the findings and participated in the writing. E.L.F. participated in the conception and design of the study, helped to interpret findings and contributed substantially to the writing.

Acknowledgements: The authors thank the French Food Banks Federation for their help in the realisation of the study.

\section{References}

1 Observatoire National de la Pauvreté et de l'Exclusion Sociale. Les travaux 2005-2006. La Documentation Française. Paris: Observatoire National de la Pauvreté et de l'Exclusion Sociale, 2006.

2 James WP, Nelson M, Ralph A, Leather S. Socioeconomic determinants of health. The contribution of nutrition to inequalities in health. British Medical Journal 1997; 314: 1545-9.

3 Vozoris NT, Tarasuk VS. Household food insufficiency is associated with poorer health. Journal of Nutrition 2003; 133: $120-6$.
4 Gloria L, Cravo M, Camilo ME, Resende M, Cardoso JN, Oliveira AG, et al. Nutritional deficiencies in chronic alcoholics: relation to dietary intake and alcohol consumption. American Journal of Gastroenterology 1997; 92: 485-9.

5 Ministère de la Santé. Programme National Nutrition-Santé PNNS [online], 2001. Available at http://www.sante.gouv.fr/ htm/actu/34_010131.htm.

6 Gerbouin-Gerolle P, Chabeau L. Food programmes and poor families in a suburb of Paris. In: Köhler BM, Feichtinger E, Barlösius E, Dowler E, eds. Poverty and Food in Welfare Societies. Berlin: Edition Sigma, 1997; 325-35.

7 Bellin C, Dauphin AG, Castetbon K, Darmon N. E3A: Enquête auprès des associations d'aide alimentaire. Rapport pour la Direction Générale de la Santé. Paris: Unité de Recherche en Epidémiologie Nutritionnelle et Unité de Surveillance et d'Epidémiologie Nutritionnelles, 2005. Also available at http://www.sante.gouv.fr/htm/ pointsur/nutrition/enquete_aidealim.pdf.

8 DG Agriculture. Evaluation des programmes alimentaires de la communauté européenne. Rapport final. Bruxelles: Commission européene, 2003.

9 Stigler GJ. The cost of subsistence. Journal of Farm Economy 1945; 27: 303-14.

10 Smith VE. Linear programming models for the determination of palatable human diets. Journal of Farm Economy 1959; 31: 272-83.

11 Colavita C, D'Orsi R. Linear programming and pediatric dietetics. British Journal of Nutrition 1990; 64: 307-17.

12 Soden PM, Fletcher LR. Modifying diets to satisfy nutritional requirements using linear programming. British Journal of Nutrition 1992; 68: 565-72.

13 Cleveland LE, Escobar AJ, Lutz SM, Welsh SO. Method for identifying differences between existing food intake patterns and patterns that meet nutrition recommendations. Journal of the American Dietetic Association 1993; 93: 556-63.

14 Darmon N, Ferguson EL, Briend A. Impact of a cost constraint on nutritionally adequate food choices for French women: an analysis by linear programming. Journal of Nutrition Education and Behavior 2006; 38: 82-90.

15 Briend A, Darmon N. Determining limiting nutrients by linear programming: a new approach to predict insufficient intakes from complementary foods. Pediatrics 2000; 106: 1288-9.

16 Darmon N, Ferguson E, Briend A. Linear and nonlinear programming to optimize the nutrient density of a population's diet: an example based on diets of preschool children in rural Malawi. American Journal of Clinical Nutrition 2002; 75: 245-53.

17 Darmon N, Ferguson EL, Briend A. A cost constraint alone has adverse effects on food selection and nutrient density: an analysis of human diets by linear programming. Journal of Nutrition 2002; 132: 3764-71.

18 Darmon N, Ferguson E, Briend A. Do economic constraints encourage the selection of energy dense diets? Appetite 2003; 41: 315-22.

19 Ferguson EL, Darmon N, Briend A, Premachandra IM. Foodbased dietary guidelines can be developed and tested using linear programming analysis. Journal of Nutrition 2004; 134: 951-7.

20 SU.VI.MAX/INSERM ouvrage collectif. Table de composition des aliments. Paris: Economica Editions, 2006.

21 Martin A, ed. Apports nutritionnels conseillés pour la population française, 3e ed. Paris: Lavoisier, 2001.

22 Briend A, Darmon N, Ferguson E, Erhardt JG. Linear programming: a mathematical tool for analyzing and optimizing children's diets during the complementary 
feeding period. Journal of Pediatric Gastroenterology and Nutrition 2003; 36: 12-22.

23 Cuco G, Arija V, Marti-Henneberg C, Fernandez-Ballart J. Food and nutritional profile of high energy density consumers in an adult Mediterranean population. European Journal of Clinical Nutrition 2001; 55: 192-9.

24 Drewnowski A, Darmon N. The economics of obesity: dietary energy density and energy cost. American Journal of Clinical Nutrition 2005; 82: 265S-73S.

25 Jacobs-Starkey L. An evaluation of emergency food bags. Journal of the Canadian Dietetic Association 1994; 55 : $175-8$.

26 Teron AC, Tarasuk VS. Charitable food assistance: what are food bank users receiving? Canadian Journal Public Health 1999; 90: 382-4.

27 Akobundu UO, Cohen NL, Laus MJ, Schulte MJ, Soussloff MN. Vitamins A and C, calcium, fruit, and dairy products are limited in food pantries. Journal of the American Dietetic Association 2004; 104: 811-13.

28 Darmon N, Briend A, Drewnowski A. Energy-dense diets are associated with lower diet costs: a community study of French adults. Public Health Nutrition 2004; 7: 21-7.

29 Andrieu E, Darmon N, Drewnowski A. Low-cost diets: more energy, fewer nutrients. European Journal of Clinical Nutrition 2006; 60: 434-6.

30 Drewnowski A, Darmon N, Briend A. Replacing fats and sweets with vegetables and fruit - a question of cost. American Journal of Public Health 2004; 94: 1555-9.

31 Bellin-Lestienne C, Deschamps V, Noukpoapé A, Darmon N, Hercberg S, Castetbon K. Consommations alimentaires et place de l'aide alimentaire chez les personnes incluses dans l'étude Abena, 2004-2005. Bulletin Epidémiologique Hebdomadaire 2006; 11/12: 79-81.
32 Cérani N, Camus M. Le budget des familles en 2001. INSEE Résultats - Société No. 29. Paris: Institut national de la statistique et des études économiques, 2004. Also available at http://www.insee.fr/fr/ffc/docs_ffc/irsoc29.pdf.

33 Morland K, Wing S, Diez RA, Poole C. Neighborhood characteristics associated with the location of food stores and food service places. American Journal of Preventive Medicine 2002; 22: 23-9.

34 Herman DR, Harrison GG, Jenks E. Choices made by lowincome women provided with an economic supplement for fresh fruit and vegetable purchase. Journal of the American Dietetic Association 2006; 106: 740-4.

35 Dowler E. Inequalities in diet and physical activity in Europe. Public Health Nutrition 2001; 4: 701-9.

36 Institut national de prévention et d'education à la santé, Programme National Nutrition Santé. La santé vient en mangeant. Le guide alimentaire pour tous [online], 2002. Available at http://www.lasantevientenmangeant.inpes. sante.fr/. Accessed 4 June 2007.

37 Townsend MS. Obesity in low-income communities: prevalence, effects, a place to begin. Journal of the American Dietetic Association 2006; 106: 34-7.

38 Marmot M, Wilkinson RG. Social Determinants of Health. Oxford: Oxford University Press, 1999.

39 Gibson D. Food stamp program participation is positively related to obesity in low income women. Journal of Nutrition 2003; 133: 2225-31.

40 Ahluwalia IB, Dodds JM, Baligh M. Social support and coping behaviors of low-income families experiencing food insufficiency in North Carolina. Health Education \& Behavior 1998; 25: 599-612.

41 Tarasuk VS, Beaton GH. Household food insecurity and hunger among families using food banks. Canadian Journal of Public Health 1999; 90: 109-13. 